\title{
Against the Stream: The teenage brain is not unique
}

\author{
Philip Graham
}

BJPsych Bulletin (2019) 43, 287-289, doi:10.1192/bjb.2019.37

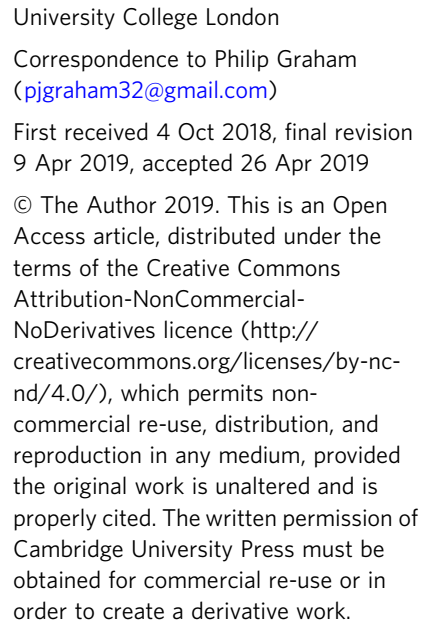

Increasingly, claims are being made by developmental neuroscientists that adolescence is characterised by unique changes to the brain. These changes are said to underlie what are claimed to be unique behavioural features of the teenage years. In this paper, it is argued that the brain changes described begin before the teen years and continue long after them. This is not surprising, as there are no behavioural features that are specific to adolescence.

Declaration of interest None.

Keywords Adolescence; brain development; teenagers; neuroimaging.
The neuroscientist Sarah-Jayne Blakemore is the leading pioneer in the field of adolescent brain development. Her research, bridging as it does neuroscience and behaviour, has vastly increased our knowledge of this previously neglected area. 'Until about 15 or 20 years ago,' she is quoted as saying in an interview with The Guardian, ' 'we just didn't know that the brain develops at all within the teenage years. Until then, it was assumed that teenage behaviour was almost entirely down to hormonal changes in puberty, but brain scans and psychological experiments have now found that adolescence is a critical period of neurological change, much of which is responsible for the unique characteristics of adolescent behaviour'. Far from being a defective or inferior version of an adult brain, the interview continues, the adolescent mind is both unique and - to Blakemore beautiful. 'Teenagers,' she says, are brilliant'.

Others, who popularise findings such as Blakemore's, are even more exuberant in their descriptions and explanations of adolescent behaviour. The neurologist Frances Jensen, in her book Secrets of the Teenage Brain, asks: 'So what happens when they reach fourteen, fifteen or sixteen years old? How is it that the cute, even-tempered, happy and well-behaved child you've known for more than a decade is suddenly someone you don't know at all?"2 (p. 15). After discarding other possibilities, the author decides 'we have to look at their brain circuits for answers.' She then adds, 'Adolescence is a time of true wonder. Because of the flexibility and growth of the brain, adolescents have a window of opportunity with an increased capacity for remarkable accomplishments $^{2}$ (p. 22).

There are six questionable assumptions in statements such as these by neuroscientists, all of which have profound implications for the way adolescents are considered by psychiatrists and more generally in our society.

a) Adolescence is a well-defined phase of life that can be defined biologically.

b) Although all are agreed that development is a progressive process from childhood, through adolescence to adulthood, there are maturational developments in the brain that are specific to adolescence.

c) There are clear-cut changes in behaviour and cognitive development that characterise adolescence and distinguish it from other phases of life.

d) Each of the behaviours regarded as characteristic of adolescents, such as moodiness, risk-taking and impulsive decision-making, can be traced to changes in those parts of the brain responsible for their control.

e) Adolescence therefore presents a window of opportunity, a sensitive or even a critical period for learning and personality development.

f) When adolescents show disturbances of behaviour or emotional life, though taking context into account, one should look for explanations in the way their brains are developing.

Let me examine each of these assumptions in turn.

Adolescence is a well-defined phase of life that can be defined biologically. Most definitions of adolescence date its onset from the beginning of puberty and its end-point as the gaining of significant social independence. For example, adolescence has recently been defined as 'the period marking the transition from childhood to adulthood. Historically, this typically spans from 12 to 18 years of age, which roughly corresponds to the time from pubertal onset (i.e. specific 
hormonal changes) to guardian independence,. ${ }^{3}$ Thus, its beginning is defined biologically and its end socially. From what point, however, should one time the start of puberty? From so-called adrenarche, occurring usually between the ages of nine and eleven years, when there is a modest increase in secretion of sex hormones and sexual attraction to the same or opposite gender is first clearly experienced? ${ }^{4}$ Or, as has been the case until relatively recently, from the point roughly 2 years later when the first visible signs of secondary sexual characteristics (breast changes in girls and pubic hair in boys) appear? ${ }^{5}$ There are also significant problems with using a social criterion to define the end of adolescence. Even within Western society - and the problems are far greater if one looks at other parts of the world some young people leave school and enter employment at 16 years old, while others remain dependent and continue post-graduate studies until their mid-to-late twenties.

Owing to these difficulties in definition, henceforth in this article I shall refer not to adolescents, but to teenagers (i.e. those between 13 and 19 years old). This is the way most of the general public thinks of adolescents and, indeed, when they discuss adolescent development it is also, in practice, the way neuroscientists refer to it.

There are maturational developments in the brain that are specific to the teenage years. From the late 1980s onwards, structural studies of the teenage brain have revealed that there is an increase in white matter and, owing to synaptic pruning, a reduction of grey matter during the teen years. However, it has become apparent that both these structural changes begin well before the teen years and continue into young and even older adulthood. For example, in a longitudinal study of 5-32-year-olds it was reported that 'When individual subjects were examined, almost all of the younger subjects $(>95 \%)$ demonstrated increases of white matter volume from their first to last scan, and the majority of subjects $(50-80 \%)$ in the older age groups (15-32 years, representing adolescence and young adulthood) continued to demonstrate white matter volume increases between scans ( $\sim 4$ years apart on average), ${ }^{6}$ A further study indicated that cortical grey matter volume is at its highest in childhood, decreasing steadily through the second decade with deceleration in the third decade, while cortical white matter volume increases until mid-to-late adolescence before decelerating. These findings, the authors point out, are in contrast to previous, widely publicised suggestions that cortical grey matter volume peaks around the onset of puberty. ${ }^{7}$ The authors of another study showing that thinning of white matter is higher between the ages of 12-19 years than earlier in childhood or later in young adulthood claim this reveals that 'adolescence marks a unique feature of brain development. ${ }^{8}$ However, the use of the word 'unique' is surely inaccurate when it is clear that white matter thinning proceeds, albeit at a somewhat slower pace, both before and after the teen years.

There are clear-cut changes in behaviour and cognitive development that begin at the onset of adolescence and continue throughout it. Since the concept of adolescent turmoil was disputed many years ago ${ }^{9}$ there has been a small but steady stream of studies showing that it is continuity rather than discontinuity that characterises the behavioural transition from childhood to adulthood. Thus, remarkable stability has been found in five different measures of personality traits over a period of 3 years in a large sample of children and teenagers with a mean age at time 1 of 10.9 years (range 7-15) and time 2 of 13.9 years (range 10-18). ${ }^{10}$ The existence in the 1980s of a substantial number of antisocial teenagers who had not shown antisocial behaviour in childhood and whose antisocial behaviour did not persist into adulthood ${ }^{11}$ might suggest that there are indeed brain changes in the teens underlying antisocial behaviour. However, in the same study it was argued that this upsurge of adolescent antisocial behaviour only occurs when the environment is highly criminogenic. When teenagers live in a time-period when the rate of crime is low, adolescent-limited antisocial behaviour is barely detectable. It is not change in the brain but change in the environment that is responsible for adolescence-limited antisocial behaviour. This illustrates the importance of taking social and historical context into account when explaining behavioural changes over time.

Each of the behaviours regarded as characteristic of adolescents, such as risk-taking and impulsive decision-making, can be traced to changes in those parts of the brain responsible for their control. Remarkable advances have been made over the past 20 years in linking changes in, for example, executive function and social cognition, ${ }^{12}$ sensation-seeking and impulsivity, ${ }^{13}$ and taking the perspective of another person ${ }^{14}$ to changes in the brain in the teen years. In none of these, however, has the linkage been shown to be specific to the teen years or to adolescence, however that might be defined. For example, risk-taking is often regarded as a particular feature of the teen years. The triadic systems theory has been put forward to explain this phenomenon. ${ }^{15}$ This postulates that adolescents are particularly prone to take risks because the maturation of the pre-frontal cortex (which is responsible for cognitive appraisal of a situation) is out of step with the maturation of the sub-cortical systems responsible for affect and motivation. Thus, immature adolescent emotions override mature cognitions. However, it has been pointed out, first, that real-life studies show that the peak age for much risk-taking behaviour occurs not in the teen years but in the 20s and, second, that such age differences in risk taking as do exist are due less to asynchrony in brain development timelines than to differences between adolescents and adults in the situational factors that they find tempting or rewarding. ${ }^{16}$ The fact that teenagers find certain rewards more appealing than do adults is surely at least partly explained by their exposure to targeted marketing.

Adolescence presents a unique window of opportunity, a sensitive or even a critical period for learning and personality development. The notion of the teen years as a unique 'window of opportunity' for learning and behaviour is based on the idea that the development of the brain at this phase of life is undergoing unique, never to be repeated changes. However, the evidence for such a sensitive period is weak. It has been examined in a range of cognitive processes, using an animal model, with the finding that 'the strongest evidence for sensitive periods to date comes from rodent studies showing a heightened vulnerability to the disruptive effects of social isolation and cannabis use, as well as reduced fear extinction learning. There is little conclusive evidence for human adolescence, however. ${ }^{,}{ }^{17}$ A similar conclusion in relation to adolescence as a sensitive period has been drawn in relation to sociocultural processing. ${ }^{18}$ 
Enormous resources have already been invested in secondary education. Young people in their mid-to-late teens are already subjected to intense pressure to study for public examinations. Some, at least, suffer pathological anxiety and depression as a result. Adolescent researchers themselves have pointed to the exceptional stress teenagers experience as a result of public examinations and would certainly not agree with adding to their stress. However, the idea that this phase of life presents a unique opportunity for learning does risk opening the door to the idea that even more knowledge be packed into teenagers because, if it isn't, they might be ignorant for ever. In fact, windows of opportunity never close. Of the 174000 undergraduate and postgraduate students at the Open University in 2015/2016, approximately $10 \%$ were over the age of 55 years. ${ }^{19}$ For them, the 'window of opportunity' had opened much later than the teens.

When adolescents show disturbances of behaviour or emotional life, one should first look for explanations in the way their brains are developing. It is the case that most types of mental disorder (depression, anxiety, schizophrenia, eating disorders, obsessional disorders) most commonly first manifest in the teen years. However, as we have seen, this cannot be because of the unique features of brain development at this phase of life, as such unique features do not exist. Further, the mental disorder for which there is probably the best-documented evidence of a link with brain function, namely attention-deficit hyperactivity disorder, ${ }^{20}$ nearly always begins in early childhood, not the teen years. Instead, if psychiatrists wish to pinpoint the reasons for behavioural change in adolescence when it occurs, they should examine features such as family disharmony, examination stress, exposure to social media and, most significantly, the 'maturity gap' (between physical and mental maturity and lack of control over their own lives) to which teenagers are particularly exposed. These form part of the social construction that we, in the West, call adolescence. ${ }^{21}$

Finally, Blakemore's generalisation about adolescents, that they are 'brilliant', is also questionable. Although some, particularly the most antisocial, are definitely not at all brilliant in any meaningful sense of that word, a large number of them undoubtedly are. Yet so are a large number of twenty-somethings, thirty-somethings and so on. So, although I certainly would not count myself among them, are a number of eighty-somethings. Whether people of any age are or are not 'brilliant' is surely not best explained with reference to their brain development.

\section{About the author}

Philip Graham is Emeritus Professor of Child Psychiatry at the Institute of Child Health, University College London, UK.

\section{References}

1 Kellaway K. Sarah-Jayne Blakemore: it is strangely acceptable to mock and demonise teenagers. Guardian, 17 August 2018.

2 Jensen F. Secrets of the Teenage Brain. Harper/Collins, 2015

3 Jaworska N, MacQueen G. Adolescence as a unique developmental period. J Psychiat Neurosci 2015; 40(5): 291-3.

4 Herdt G, McClintock M. The magical age of ten. Arch Sex Behav 2000; 29(6): 587-606.

5 Tanner J. Fetus Into Man. Cambridge University Press, 1990

6 Lebel C, Beaulieu C. Longitudinal development of human brain wiring continues from childhood into adulthood. J Neurosci 2011; 31(30): 10937-47.

7 Mills KL, Goddings A-L, Herting MM, Meuwese R, Blakemore S-J, Crone EA, et al. Structural brain development between childhood and adulthood: convergence across four longitudinal samples. Neurolmage 2016; 141: 273-81.

8 Zhou D, Lebel C, Treit S, Evans A, Beaulieu C. Accelerated longitudinal cortical thinning in adolescence. Neurolmage 2015; 104: 138-45.

9 Rutter M, Graham P, Chadwick O, Yule W. Adolescent turmoil: fact or fiction? J Child Psychol Psychiat 1976; 17: 35-56.

10 De Fruyt F, Bartels M, Van Leeuwen KG, De Clercq B, Decuyper $M$, Mervielde I. Five types of personality continuity in childhood and adolescence. J Pers Soc Psychol 2006; 91(3): 538-52.

11 Moffitt T. Adolescence limited and life course persistent antisocial behaviour: a developmental taxonomy. Psychol Taxonom 1993; 100: 674-701.

12 Blakemore S-J, Choudhury S. Development of the adolescent brain: implications for executive function and social cognition. J Child Psychol Psychiat 2006; 47(3-4): 296-312.

13 Steinberg L, Albert D, Cauffman E, Banich M, Graham S, Woolard J. Age differences in sensation seeking and impulsivity as indexed by behavior and self-report: evidence for a dual systems model. Develop Psychol 2008; 44: 1764-8.

14 Dumontheil I, Apperly I, Blakemore S-J. Online usage of theory of mind continues to develop in late adolescence. Develop Sci 2010; 13: 331-8.

15 Casey B, Jones R, Somerville L. Braking and accelerating of the adolescent brain. J Res Adol 2011; 21(1): 21-33.

16 Willoughby T, Tavernier R, Hamza C, Adachi P, Good M. The triadic systems model perspective and adolescent risk taking. Brain Cogn 2014; 89: 114-5

17 Fuhrmann D, Knoll $\sqcup$, Blakemore SJ. Adolescence as a sensitive period of brain development. Trends Cogn Sci 2015; 19(10): 558-66.

18 Blakemore S-J, Mills K. Is adolescence a sensitive period for sociocultural processing? Ann Rev Psychol 2014; 65: 187-207.

19 Open University. Facts and Figures. Open University, 2017.

20 Yu-Feng Z, Yong H, Chao-Zhe Z, Qing-Jiu C, Man-Qiu S, Meng L, et al. Altered baseline brain activity in children with ADHD revealed by resting-state functional MRI. Brain Dev 2007; 29: 83-91.

21 Graham P. The End of Adolescence. Oxford University Press, 2004 